\title{
Prediction of Methane Production from Dairy and Beef Cattle
}

\author{
J. L. Ellis, ${ }^{11}$ E. Kebreab, ${ }^{*}$ N. E. Odongo, ${ }^{*}$ B. W. McBride, ${ }^{*}$ E. K. Okine, $\dagger$ and J. France* \\ ${ }^{*}$ Centre for Nutrition Modelling, Department of Animal and Poultry Science, University of Guelph, Guelph, Ontario, N1G 2W1, Canada \\ †Department of Agricultural, Food and Nutritional Science, University of Alberta, Edmonton, Alberta, T6G 2P5, Canada
}

\begin{abstract}
Methane $\left(\mathrm{CH}_{4}\right)$ is one of the major greenhouse gases being targeted for reduction by the Kyoto protocol. The focus of recent research in animal science has thus been to develop or improve existing $\mathrm{CH}_{4}$ prediction models to evaluate mitigation strategies to reduce overall $\mathrm{CH}_{4}$ emissions. Eighty-three beef and 89 dairy data sets were collected and used to develop statistical models of $\mathrm{CH}_{4}$ production using dietary variables. Dry matter intake (DMI), metabolizable energy intake, neutral detergent fiber, acid detergent fiber, ether extract, lignin, and forage proportion were considered in the development of models to predict $\mathrm{CH}_{4}$ emissions. Extant models relevant to the study were also evaluated. For the beef database, the equation $\mathrm{CH}_{4}(\mathrm{MJ} / \mathrm{d})=2.94( \pm 1.16)+$ $0.059( \pm 0.0201) \times$ metabolizable energy intake $(\mathrm{MJ} / \mathrm{d})$ $+1.44( \pm 0.331) \times$ acid detergent fiber $(\mathrm{kg} / \mathrm{d})-4.16( \pm$ $1.93) \times$ lignin $(\mathrm{kg} / \mathrm{d})$ resulted in the lowest root mean square prediction error (RMSPE) value (14.4\%), $88 \%$ of which was random error. For the dairy database, the equation $\mathrm{CH}_{4}(\mathrm{MJ} / \mathrm{d})=8.56( \pm 2.63)+0.14( \pm 0.056) \times$ forage (\%) resulted in the lowest RMSPE value (20.6\%) and $57 \%$ of error from random sources. An equation based on DMI also performed well for the dairy database: $\mathrm{CH}_{4}(\mathrm{MJ} / \mathrm{d})=3.23( \pm 1.12)+0.81( \pm 0.086) \times \mathrm{DMI}$ $(\mathrm{kg} / \mathrm{d})$, with a RMSPE of $25.6 \%$ and $91 \%$ of error from random sources. When the dairy and beef databases were combined, the equation $\mathrm{CH}_{4}(\mathrm{MJ} / \mathrm{d})=3.27( \pm 0.79)$ $+0.74( \pm 0.074) \times \mathrm{DMI}(\mathrm{kg} / \mathrm{d})$ resulted in the lowest RMSPE value (28.2\%) and $83 \%$ of error from random sources. Two of the 9 extant equations evaluated predicted $\mathrm{CH}_{4}$ production adequately. However, the new models based on more commonly determined values showed an improvement in predictions over extant equations.
\end{abstract}

Key words: cattle, greenhouse gas, methane, modeling

\section{INTRODUCTION}

Globally, agriculture accounts for approximately onefifth of the projected anthropogenic greenhouse effect,

Received October 16, 2006.

Accepted March 25, 2007.

${ }^{1}$ Corresponding author: jellis@uoguelph.ca producing about $50 \%$ of overall anthropogenic methane $\left(\mathrm{CH}_{4}\right)$ emissions (IPPC, 2001). The Kyoto protocol came into effect in 2005, and the signatories have committed to reducing emissions to an agreed level. For example, Canada has committed to reducing greenhouse gas emissions to 6\% below 1990 levels between 2008 and 2012 (Environment Canada, 2005). Methane from agriculture arises primarily from enteric fermentation; therefore, ruminants (especially beef and dairy cattle) are mainly responsible for enteric emissions of $\mathrm{CH}_{4}$ (Kebreab et al., 2006). As a result of the Kyoto protocol, the focus of recent research in animal science has been to provide mitigation strategies to reduce overall $\mathrm{CH}_{4}$ production from ruminants. Although most of the research in the past on $\mathrm{CH}_{4}$ production has focused on emissions from an energetic inefficiency standpoint (e.g., Moe and Tyrrell, 1979a; Belyea et al., 1985), attention has now shifted toward its contribution to climatic change and global warming (e.g., Benchaar et al., 2001; Boadi et al., 2004).

Mathematical models allow us to predict $\mathrm{CH}_{4}$ production from cattle without undertaking extensive and costly experiments. The models used can be classified as either statistical models, which relate nutrient intake to $\mathrm{CH}_{4}$ production directly, or dynamic mechanistic models, which estimate $\mathrm{CH}_{4}$ production using mathematical descriptions of rumen fermentation biochemistry (Kebreab et al., 2006). Although many statistical models have been fairly successful in predicting $\mathrm{CH}_{4}$ production, many have inputs that are not commonly measured and some may have difficulty predicting $\mathrm{CH}_{4}$ production outside the range of values on which they were developed (Wilkerson et al., 1995). These problems may be addressed by using commonly measured equation input variables and by developing models on expansive data sets compiled from multiple sources.

The objectives of this study were 1) to develop statistical models of $\mathrm{CH}_{4}$ production on beef and dairy data using commonly measured dietary variables, and to determine the factors that appear to have a significant relationship with $\mathrm{CH}_{4}$ production, and 2) to challenge extant $\mathrm{CH}_{4}$ prediction models against a $\mathrm{CH}_{4}$ database containing beef and dairy cattle data. 
Table 1. Summary of the database

\begin{tabular}{|c|c|c|c|c|c|c|c|c|c|}
\hline \multirow[b]{2}{*}{ Source } & \multirow[b]{2}{*}{ Breed } & \multirow[b]{2}{*}{$\mathrm{n}$} & \multirow{2}{*}{$\begin{array}{l}\text { Methane collection } \\
\text { technique }^{1}\end{array}$} & \multicolumn{2}{|c|}{ Methane, MJ/d } & \multicolumn{2}{|c|}{ DMI, kg/d } & \multicolumn{2}{|c|}{$\mathrm{BW}, \mathrm{kg}$} \\
\hline & & & & Mean & SEM & Mean & SEM & Mean & SEM \\
\hline Birkelo et al. (1986) & Beef & 2 & Whole animal calorimetry & 4.24 & 0.734 & 3.82 & 0.425 & 327 & 1.00 \\
\hline Varga et al. (1990) & Beef & 8 & Whole animal calorimetry & 7.00 & 0.314 & 5.50 & 0.278 & 305 & 2.91 \\
\hline Reynolds et al. (1991) & Beef & 4 & Whole animal calorimetry & 5.74 & 0.897 & 5.66 & 0.926 & 321 & 5.86 \\
\hline Hironaka et al. (1996) & Beef & 8 & Whole animal calorimetry & 6.17 & 0.515 & 5.28 & 0.540 & 288 & 7.57 \\
\hline McCaughey et al. (1997) & Beef & 4 & $\mathrm{SF}_{6}$ & 10.3 & 0.514 & 13.8 & 0.385 & 398 & 7.90 \\
\hline Westberg et al. (2001) & Beef & 13 & $\mathrm{SF}_{6}$ & 10.4 & 0.751 & 10.4 & 0.904 & 513 & 31.7 \\
\hline Boadi and Wittenberg (2002) & Beef & 2 & $\mathrm{SF}_{6}$ & 8.59 & 1.19 & 7.35 & 1.050 & 310 & 0.000 \\
\hline Boadi et al. (2002) & Beef & 5 & $\mathrm{SF}_{6}$ & 12.1 & 0.692 & 12.0 & 0.563 & 345 & 0.585 \\
\hline Boadi et al. (2004) & Beef & 5 & $\mathrm{SF}_{6}$ & 4.12 & 0.650 & 10.8 & 0.639 & 383 & 44.7 \\
\hline McGinn et al. (2004) & Beef & 8 & Whole animal calorimetry & 9.19 & 0.321 & 7.20 & 0.139 & 312 & 0.000 \\
\hline Beauchemin and McGinn (2005) & Beef & 4 & Whole animal calorimetry & 6.15 & 1.36 & 8.61 & 0.573 & 391 & 24.3 \\
\hline Coppock et al. (1964) & Dairy & 3 & Whole animal calorimetry & 17.0 & 0.382 & 15.2 & 0.700 & - & - \\
\hline Moe and Tyrrell (1979a) & Dairy & 6 & Whole animal calorimetry & 13.9 & 2.28 & 13.5 & 2.60 & 628 & 6.76 \\
\hline Belyea et al. (1985) & Dairy & 4 & Mask calorimetry & 8.26 & 0.284 & 5.44 & 0.509 & 250 & 3.88 \\
\hline Holter et al. (1986) & Dairy & 5 & Whole animal calorimetry & 10.4 & 0.412 & 9.50 & 0.339 & 617 & 20.5 \\
\hline Holter et al. (1990) & Dairy & 5 & Whole animal calorimetry & 13.5 & 0.987 & 18.4 & 0.156 & 571 & 4.41 \\
\hline Holter et al. (1992) & Dairy & 7 & Whole animal calorimetry & 11.6 & 0.524 & 16.9 & 0.425 & 536 & 8.78 \\
\hline Tyrrell et al. (1992) & Dairy & 8 & Whole animal calorimetry & 5.31 & 0.178 & 4.59 & 0.053 & 268 & 2.44 \\
\hline \multirow[t]{2}{*}{ Sauer et al. (1998) } & Dairy & 23 & Micrometeorological mass & & & & & & \\
\hline & & & balance technique & 22.3 & 0.262 & 16.3 & 0.282 & 600 & 0.000 \\
\hline Waldo et al. (1997) & Dairy & 8 & Whole animal calorimetry & 9.22 & 0.182 & 6.87 & 0.119 & 333 & 0.940 \\
\hline Westberg et al. (2001) & Dairy & 3 & $\mathrm{SF}_{6}$ & 18.9 & 4.82 & 14.5 & 3.42 & 673 & 0.000 \\
\hline Boadi and Wittenberg (2002) & Dairy & 2 & $\mathrm{SF}_{6}$ & 8.91 & 0.847 & 7.15 & 1.05 & 310 & 0.000 \\
\hline
\end{tabular}

${ }^{1} \mathrm{SF}_{6}=$ sulfur hexafluoride tracer gas technique.

\section{MATERIALS AND METHODS}

\section{Database}

The database consisted of 83 beef and 89 dairy data sets from 29 published papers from the literature spanning 1964 to 2005. Criteria for selection were that the research was done in either the northern United States or Canada, to ensure similarity of feedstuffs and climate, and that $\mathrm{CH}_{4}$ production as well as an adequate description of the animals and chemical composition of the diet was provided. A summary of the publications composing the database is presented in Table 1 . Wherever possible, missing values were replaced with book values from Conrad (1982) and the NRC (1996, 2001). Dry matter intake, ME intake (MEI), ADF, NDF, ether extract (EE), lignin, and forage proportion were available for most data sets and were thus used for regression equation development. The database was subdivided into dairy, beef, and a combination of the 2 , and is summarized in Table 2.

\section{Statistical Analysis}

The correlations among the dietary variables were determined using PROC CORR (SAS Institute, 2000).
Cook's distance test (Der and Everitt, 2002) was performed on the data, and outliers were removed from subsequent analysis. Outliers were identified as data points with a large value of Cook's distance statistic that also had a large influence on the resultant regression line.

The main effects (DMI kg/d, MEI Mcal/d, ADF kg/d, $\mathrm{NDF} \mathrm{kg} / \mathrm{d}, \mathrm{EE} \mathrm{kg} / \mathrm{d}$, lignin $\mathrm{kg} / \mathrm{d}$, and forage proportion $\%$ ) were analyzed using PROC MIXED (SAS Institute, 2000). The mixed model analysis was chosen because the data were gathered from multiple studies; therefore, it was necessary to consider analyzing not only fixed effects of the dependent variables, but also random effects (because the studies represented a random sample of a larger population of studies). Distribution of random effects was assumed to be normal and the dual quasi-Newton technique was used for optimization with an adaptive Gaussian quadrature as the integration method (SAS Institute, 2000). Analysis was performed with an assumption of variance distribution for the fixed factor to be normal or gamma (SAS Institute, 2000). Observed $\mathrm{CH}_{4}$ production rates were weighted by the $\mathrm{n}$ of the study (Table 1), and if the random covariance or the random slope was not significant, they were removed from the model (St-Pierre, 2001). 
Table 2. Summary of the beef, dairy, and combined databases

\begin{tabular}{|c|c|c|c|c|c|c|c|c|c|c|c|c|}
\hline \multirow[b]{3}{*}{ Variable } & \multicolumn{12}{|c|}{ Database $^{1}$} \\
\hline & \multicolumn{4}{|c|}{ Beef } & \multicolumn{4}{|c|}{ Dairy } & \multicolumn{4}{|c|}{ Combined } \\
\hline & Mean & SEM & Min & Max & Mean & SEM & Min & Max & Mean & SEM & Min & Max \\
\hline $\mathrm{CH}_{4}, \mathrm{MJ} / \mathrm{d}$ & 9.13 & 0.0937 & 2.81 & 17.2 & 14.3 & 0.157 & 4.31 & 24.9 & 11.8 & 0.103 & 2.81 & 24.9 \\
\hline $\mathrm{ME}$ intake, MJ/d & 71.1 & 0.641 & 27.3 & 114 & 134 & 1.53 & 31.9 & 231 & 27.6 & 0.180 & 13.4 & 82.7 \\
\hline DMI, kg/d & 8.16 & 0.328 & 3.40 & 14.4 & 12.5 & 0.540 & 4.19 & 20.1 & 10.6 & 0.362 & 3.40 & 20.1 \\
\hline $\mathrm{NDF}, \%$ of $\mathrm{DM}$ & 47.0 & 1.71 & 19.6 & 77.2 & 39.5 & 1.32 & 18.2 & 73.1 & 4.18 & 0.146 & 0.742 & 8.62 \\
\hline $\mathrm{ADF}, \mathrm{kg} / \mathrm{d}$ & 2.35 & 0.152 & 0.298 & 5.75 & 2.92 & 0.1055 & 1.23 & 5.79 & 28.3 & 0.821 & 3.50 & 53.5 \\
\hline Lignin, \% of DM & 5.71 & 0.192 & 2.10 & 9.48 & 5.93 & 0.6890 & 1.84 & 23.4 & 5.83 & 0.367 & 1.22 & 23.4 \\
\hline Lignin, kg/d & 0.418 & 0.0252 & 0.104 & 1.11 & 0.568 & 0.0365 & 0.164 & 1.72 & 0.513 & 0.0245 & 0.104 & 1.72 \\
\hline Ether extract, $\%$ of DM & 3.29 & 0.166 & 1.42 & 8.30 & 3.68 & 0.1325 & 1.90 & 8.63 & 0.369 & 0.0187 & 0.0474 & 1.12 \\
\hline Ether extract, kg/d & 0.256 & 0.0174 & 0.0474 & 0.830 & 0.474 & 0.0310 & 0.0880 & 1.45 & 3.38 & 0.0944 & 1.40 & 8.30 \\
\hline Forage, $\%$ & 79.0 & 3.27 & 9.00 & 100 & 68.9 & 2.73 & 28.1 & 100 & 74.8 & 2.11 & 9.00 & 100 \\
\hline BW, kg & 411 & 13.5 & 206 & 662 & 528 & 16.0 & 240 & 740 & 472 & 11.4 & 206 & 740 \\
\hline
\end{tabular}

${ }^{1}$ Min = minimum value in database $; \max =$ maximum value in database .

The predictive ability of equations from Kriss (1930), Axelsson (1949), Blaxter and Clapperton (1965), Moe and Tyrrell (1979b), and Mills et al. (2003) was compared using inputs from the 3 databases. The extant equations used are presented in Table 3 . These equations were selected for comparison because they are commonly used and their input variables were obtainable from the compiled database.

Models developed in this study and extant models were evaluated using mean square prediction error (MSPE), calculated as:

$$
\operatorname{MSPE}=\sum_{i=1}^{n}\left(O_{i}-P_{i}\right)^{2} / n
$$

where $O_{i}$ is the observed value, $P_{i}$ is the predicted value, and $n$ is the number of observations. Square root of the MSPE (RMSPE), expressed as a proportion of the observed mean, gives an estimate of the overall predic- tion error. Values of RMSPE are expressed relative to the observed mean, as opposed to the predicted mean, so that comparisons of RMSPE (\%) values can be made between equations with different predicted means and so that deviation from observed values can be evaluated. The MSPE was decomposed into random error (ED), error due to deviation of the regression slope from unity (ECT), and error due to overall bias (ER; Bibby and Toutenburg, 1977).

\section{RESULTS AND DISCUSSION}

\section{Simple Regression Equations}

In agreement with previously published studies (Axelsson, 1949; Johnson and Johnson, 1995; Mills et al., 2003), DMI (kg/d) and MEI (MJ/d) were, on average, the best predictors of $\mathrm{CH}_{4}$ production in this study. The correlation analysis using observed $\mathrm{CH}_{4}$ weighted by

Table 3. List of published equations used to predict $\mathrm{CH}_{4}$ production from beef and dairy cows

\begin{tabular}{|c|c|}
\hline Source & Equation $^{1}$ \\
\hline Kriss (1930) & $\mathrm{CH}_{4}(\mathrm{MJ} / \mathrm{d})=75.42+94.28 \times \mathrm{DMI}(\mathrm{kg} / \mathrm{d}) \times 0.05524\left(\mathrm{MJ} / \mathrm{g}\right.$ of $\left.\mathrm{CH}_{4}\right)$ \\
\hline Axelsson (1949) & $\mathrm{CH}_{4}(\mathrm{MJ} / \mathrm{d})=-2.07+2.636 \times \mathrm{DMI}(\mathrm{kg} / \mathrm{d})-0.105 \times \mathrm{DMI}(\mathrm{kg} / \mathrm{d})^{2}$ \\
\hline Blaxter and Clapperton (1965) & $\begin{array}{l}\mathrm{CH}_{4}(\mathrm{MJ} / \mathrm{d})=5.447+0.469 \times(\text { energy digestibility at maintenance intake, } \% \text { of GE }) \\
+ \text { multiple of maintenance } \times[9.930-0.21 \times(\text { energy digestibility at maintenance intake, } \% \\
\text { of } \mathrm{GE}) / 100 \times \mathrm{GEI}, \mathrm{MJ} / \mathrm{d}]\end{array}$ \\
\hline Moe and Tyrrell (1979b) & $\mathrm{CH}_{4}(\mathrm{MJ} / \mathrm{d})=0.341+0.511 \times \mathrm{NSC}(\mathrm{kg} / \mathrm{d})+1.74 \times \mathrm{HC}(\mathrm{kg} / \mathrm{d})+2.652 \times \mathrm{C}(\mathrm{kg} / \mathrm{d})$ \\
\hline \multirow[t]{3}{*}{ Mills et al. (2003) } & Linear 1: $\mathrm{CH}_{4}(\mathrm{MJ} / \mathrm{d})=5.93+0.92 \times \mathrm{DMI}(\mathrm{kg} / \mathrm{d})$ \\
\hline & Linear $2: \mathrm{CH}_{4}(\mathrm{MJ} / \mathrm{d})=8.25+0.07 \times \mathrm{ME}$ intake $(\mathrm{MJ} / \mathrm{d})$ \\
\hline & Nonlinear 2: $\mathrm{CH}_{4}(\mathrm{MJ} / \mathrm{d})=45.89-(45.89+0) \times \mathrm{e}^{[-0.003 \times \mathrm{MEI}(\mathrm{MJ} / \mathrm{d})]}$ \\
\hline
\end{tabular}

\footnotetext{
${ }^{1} \mathrm{GE}=$ gross energy; $\mathrm{GEI}=$ gross energy intake; $\mathrm{HC}=$ hemicellulose $; \mathrm{C}=$ cellulose.
} 
Table 4. Correlations between dietary variables and $\mathrm{CH}_{4}$ production $(\mathrm{MJ} / \mathrm{d})$ for the beef, dairy, and combined (beef and dairy) databases

\begin{tabular}{|c|c|c|c|c|c|c|}
\hline Variable & $\mathrm{CC}^{1}$ & $P$-value & $\mathrm{R}^{2}$ & $\mathrm{CC}^{1}$ & $P$-value & $\mathrm{R}^{2}$ \\
\hline & & Beef $(\mathrm{kg} / \mathrm{d})^{4}$ & 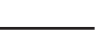 & $\longrightarrow$ & - Beef $(\%)^{5}-$ & \\
\hline DMI, kg/d & 0.661 & $<0.0001$ & 0.437 & - & - & - \\
\hline ME intake, MJ/d & 0.602 & $<0.0001$ & 0.362 & - & - & - \\
\hline NDF & 0.791 & $<0.0001$ & 0.626 & 0.454 & $<0.0001$ & 0.206 \\
\hline $\mathrm{ADF}$ & 0.741 & $<0.0001$ & 0.549 & 0.440 & $<0.0001$ & 0.194 \\
\hline Ether extract & 0.585 & $<0.0001$ & 0.342 & -0.202 & 0.0934 & 0.0408 \\
\hline Lignin & 0.0822 & 0.500 & 0.0068 & -0.488 & $<0.0001$ & 0.238 \\
\hline \multirow[t]{2}{*}{ Forage, $\%$} & - & - & - & 0.325 & 0.0061 & 0.106 \\
\hline & & \multicolumn{2}{|l|}{ Dairy $(\mathrm{kg} / \mathrm{d})^{4}$} & & - Dairy $(\%)^{5}$ & \\
\hline DMI, kg/d & 0.799 & $<0.0001$ & 0.638 & - & - & - \\
\hline ME intake, MJ/d & 0.726 & $<0.0001$ & 0.527 & - & - & - \\
\hline NDF & 0.662 & $<0.0001$ & 0.439 & -0.603 & $<0.0001$ & 0.364 \\
\hline $\mathrm{ADF}$ & 0.584 & $<0.0001$ & 0.341 & -0.626 & $<0.0001$ & 0.392 \\
\hline Ether extract & 0.915 & $<0.0001$ & 0.837 & 0.164 & 0.135 & 0.027 \\
\hline Lignin & 0.333 & 0.0043 & 0.111 & -0.623 & $<0.0001$ & 0.389 \\
\hline Forage, ${ }^{2} \%$ & - & - & - & -0.466 & $<0.0001$ & 0.217 \\
\hline \multirow[t]{2}{*}{ Forage, ${ }^{3} \%$} & - & - & - & 0.670 & $<0.0001$ & 0.449 \\
\hline & $\bar{\longrightarrow}$ & \multicolumn{2}{|l|}{ Combined $(\mathrm{kg} / \mathrm{d})^{4}$} & & Combined $(\%)^{5}$ & \\
\hline DMI, kg/d & 0.827 & $<0.0001$ & 0.685 & - & - & - \\
\hline MEI, MJ/d & 0.775 & $<0.0001$ & 0.600 & - & - & - \\
\hline NDF & 0.649 & $<0.0001$ & 0.421 & -0.242 & 0.0025 & 0.0588 \\
\hline $\mathrm{ADF}$ & 0.596 & $<0.0001$ & 0.355 & -0.247 & 0.0015 & 0.0608 \\
\hline Ether extract & 0.890 & $<0.0001$ & 0.792 & 0.119 & 0.137 & 0.0143 \\
\hline Lignin & 0.219 & 0.0081 & 0.0481 & -0.588 & $<0.0001$ & 0.345 \\
\hline Forage, ${ }^{2} \%$ & - & - & - & -0.286 & 0.0003 & 0.0820 \\
\hline Forage, ${ }^{3} \%$ & - & - & - & 0.154 & 0.143 & 0.0236 \\
\hline
\end{tabular}

${ }^{1}$ Correlation coefficients from PROC CORR (SAS Institute, 2000).

${ }^{2}$ Including all data points.

${ }^{3}$ Excluding all $100 \%$ forage data points.

${ }^{4}$ Variables NDF, ADF, ether extract, and lignin expressed in $\mathrm{kg} / \mathrm{d}$.

${ }^{5}$ Variables NDF, ADF, ether extract, and lignin expressed in \% DMI.

study in the combined database showed that DMI predicted $\mathrm{CH}_{4}$ production with an $\mathrm{R}^{2}$ of 0.69 and MEI with an $\mathrm{R}^{2}$ of 0.60 . In the dairy database, DMI predicted $\mathrm{CH}_{4}$ production with an $\mathrm{R}^{2}$ of 0.64 and MEI with an $\mathrm{R}^{2}$ of 0.53 . In the beef database, DMI predicted $\mathrm{CH}_{4}$ production with an $\mathrm{R}^{2}$ of 0.44 and MEI with an $\mathrm{R}^{2}$ of 0.36 . For the beef database, NDF $(\mathrm{kg} / \mathrm{d})$ was the best predictor of $\mathrm{CH}_{4}$ production, with an $\mathrm{R}^{2}$ of 0.63 (Table 4).

The reason for the lower correlation of DMI and MEI with $\mathrm{CH}_{4}$ for the beef database is unclear. Nkrumah et al. (2006) showed that beef cow feedlot DMI is highly correlated with $\mathrm{CH}_{4}$ production. However, Basarab et al. (2005) demonstrated that different classes of beef animals, divided by animal type, physiological status, gender, weight, growth rate, activity level, and age, produce differing amounts of $\mathrm{CH}_{4}$. It is possible that combining all animals from these categories contributed to scatter in the DMI vs. $\mathrm{CH}_{4}$ relationship for the beef database. Less diversity of physiological status and diet in the dairy database could explain the higher correlation between $\mathrm{CH}_{4}$ and DMI or MEI. Method of $\mathrm{CH}_{4}$ measurement could also contribute to this variation.
The beef database was derived from experiments using calorimetry and the sulfur hexafluoride tracer gas $\left(\mathbf{S F}_{\mathbf{6}}\right)$ technique, whereas the dairy database was almost entirely calorimetry-derived data. Dividing the beef database and considering the 2 sources separately is one way to examine the differences in regression equations caused by measurement technique. However, this significantly reduces the power of the regression and should only be attempted on a larger database.

Many older equations rely on DMI or MEI to predict $\mathrm{CH}_{4}$ production; therefore, DMI- and MEI-based prediction equations were developed on our database for comparison (Table 5). Equations [1b] and [2b] predict $\mathrm{CH}_{4}$ production from beef cattle using only MEI and DMI, respectively; equations [1d] and [2d] predict $\mathrm{CH}_{4}$ production from dairy cattle using only MEI and DMI, respectively; and equations [1c] and [2c] predict $\mathrm{CH}_{4}$ production from the combined database using only MEI and DMI, respectively (Table 5). Results of the MSPE analysis are presented in Table 6. For all 3 databases, using DMI to predict $\mathrm{CH}_{4}$ production resulted in lower RMSPE and higher $R^{2}$ values than using MEI. This is 
Table 5. List of developed statistical models used to predict $\mathrm{CH}_{4}$ production from beef and dairy cows ${ }^{1}$

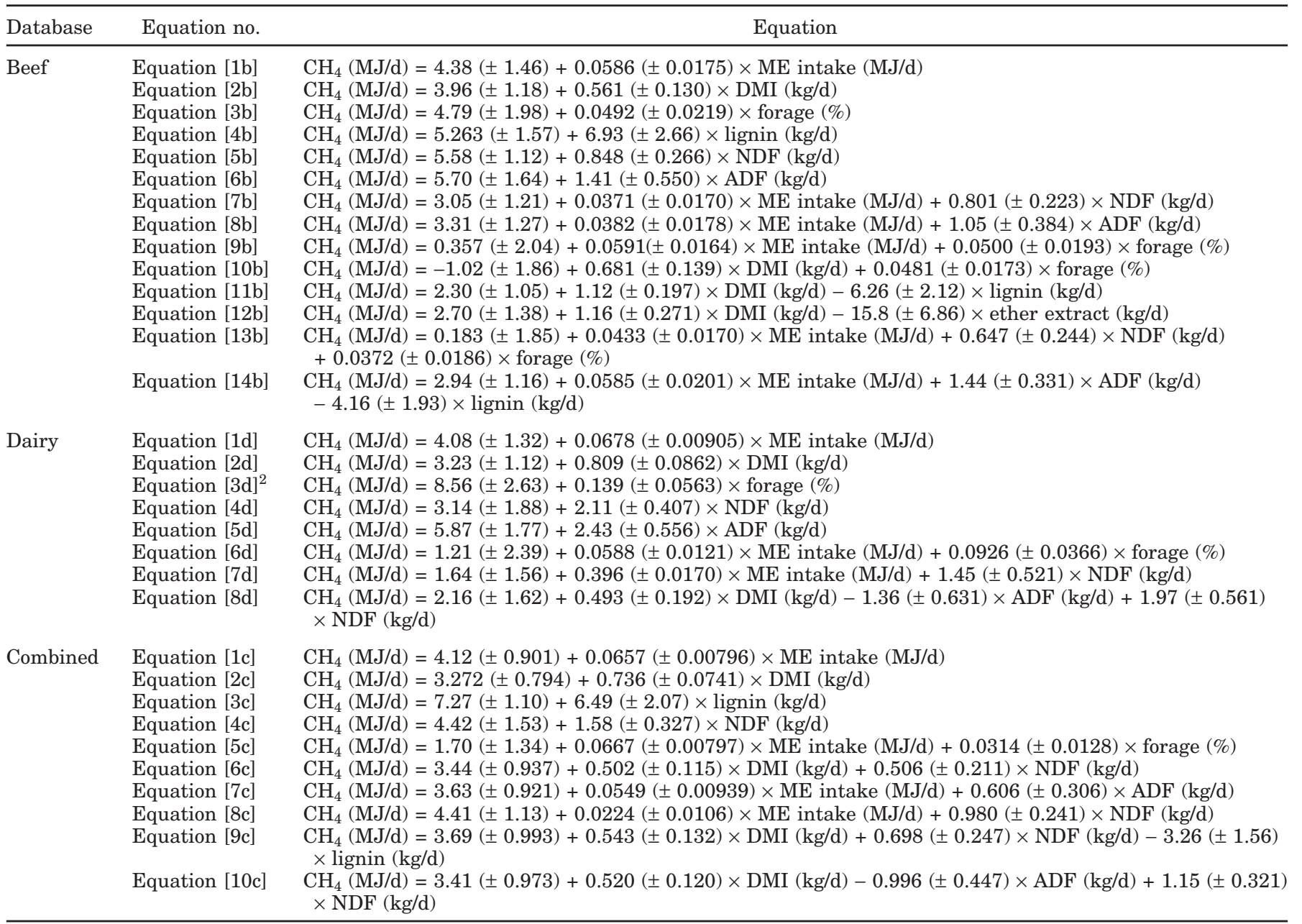

\footnotetext{
${ }^{1}$ Equation parameters are $\pm \mathrm{SE}$.

${ }^{2}$ Excluding all $100 \%$ forage data sets.
}

not surprising because all data sets reported DMI, but many MEI values were extrapolated from other information provided in the publication and are likely to contain some error compared with DMI values. In theory, MEI would be expected to have a stronger relationship with $\mathrm{CH}_{4}$ production than DMI because it accounts for $\mathrm{CH}_{4}$ production within its derivation (Mills et al., 2003).

The linear 1 and 2, and nonlinear 1 and 2 equations of Kriss (1930), Axelsson (1949), and Mills et al. (2003) all use only DMI or MEI to predict $\mathrm{CH}_{4}$ production, so they can be compared with similar equations developed here. For the beef database, the MSPE analysis showed that, although overall error was high, the equations of Axelsson (1949) and the nonlinear 2 equation of Mills et al. (2003) had lower RMSPE values than the other extant equations. The nonlinear 2 equation of Mills et al. (2003) had an RMSPE comparable to the regression equations developed in the current analysis (Table 6). For the dairy and combined databases, the nonlinear 1 and 2 equations of Mills et al. (2003) resulted in the lowest RMSPE values among the extant DMI- or MEIbased equations challenged, followed by the equation of Kriss (1930; Table 6). The nonlinear 2 equation of Mills et al. (2003) also resulted in more than $90 \%$ of error coming from random sources, a higher proportion than many of the other DMI- and MEI-based equations, and comparable to the DMI- and MEI-based equations developed in this study (Table 6). Surprisingly, although the equation of Kriss (1930) is old, its predictions resulted in comparably low RMSPE values when tested against the dairy and combined databases. Furthermore, even though the equation of Axelsson (1949) is also an older equation, its RMSPE results were comparable to the other more modern linear equations. These results indicate that older equations may still be 
Table 6. Mean square prediction error analysis for beef, dairy, and combined (beef and dairy) data sets, using new and extant $\mathrm{CH}_{4}$ prediction equations

\begin{tabular}{|c|c|c|c|c|c|c|}
\hline Data set & Equation no. & $\mathrm{RMSPE}^{1}{ }^{1}$ & ЕCT $\%^{2}$ & $\mathrm{ER} \%^{3}$ & $\mathrm{ED} \%{ }^{4}$ & $\mathrm{R}^{2}$ \\
\hline \multirow[t]{23}{*}{ Beef } & Equation [1b] & 29.7 & 2.95 & 5.70 & 91.4 & 0.37 \\
\hline & Equation [2b] & 26.4 & 4.34 & 2.84 & 92.8 & 0.44 \\
\hline & Equation [3b] & 29.4 & 4.20 & 0.374 & 95.4 & 0.21 \\
\hline & Equation [4b] & 41.1 & 2.76 & 14.9 & 82.3 & 0.01 \\
\hline & Equation [5b] & 22.3 & 3.11 & 18.0 & 78.9 & 0.67 \\
\hline & Equation [6b] & 24.3 & 0.326 & 4.02 & 95.7 & 0.56 \\
\hline & Equation $[7 b]$ & 20.6 & 3.36 & 5.40 & 91.2 & 0.69 \\
\hline & Equation [8b] & 22.0 & 4.85 & 6.53 & 88.6 & 0.66 \\
\hline & Equation [9b] & 25.2 & 3.12 & 14.8 & 82.1 & 0.61 \\
\hline & Equation [10b] & 23.2 & 5.68 & 5.21 & 89.1 & 0.65 \\
\hline & Equation [11b] & 18.7 & 3.71 & 3.74 & 92.6 & 0.74 \\
\hline & Equation [12b] & 27.0 & 15.4 & 0.754 & 83.9 & 0.48 \\
\hline & Equation [13b] & 19.5 & 3.25 & 5.36 & 91.4 & 0.74 \\
\hline & Equation [14b] & 14.4 & 5.04 & 6.99 & 88.0 & 0.85 \\
\hline & Kriss (1930) & 39.9 & 40.5 & 19.2 & 40.3 & 0.44 \\
\hline & Axelsson (1949) & 37.8 & 55.4 & 1.11 & 43.5 & 0.46 \\
\hline & Mills et al. (2003) linear 1 & 55.5 & 77.4 & 1.65 & 20.9 & 0.44 \\
\hline & Mills et al. (2003) linear 2 & 53.8 & 72.4 & 0.49 & 27.1 & 0.36 \\
\hline & Mills et al. (2003) linear 4 & 86.3 & 90.0 & 2.10 & 7.91 & 0.52 \\
\hline & Mills et al. (2003) nonlinear 1 & 41.1 & 45.5 & 17.1 & 37.4 & 0.45 \\
\hline & Mills et al. (2003) nonlinear 2 & 28.7 & 0.264 & 4.69 & 95.0 & 0.36 \\
\hline & Moe and Tyrrell (1979b) & 41.6 & 0.0795 & 38.9 & 61.0 & 0.14 \\
\hline & Blaxter and Clapperton (1965) & 19.1 & 12.2 & 8.59 & 79.3 & 0.67 \\
\hline \multirow[t]{17}{*}{ Dairy } & Equation $[1 \mathrm{~d}]$ & 29.3 & 6.72 & 0.62 & 92.7 & 0.53 \\
\hline & Equation [2d] & 25.6 & 5.19 & 3.90 & 90.9 & 0.65 \\
\hline & Equation [3d] & 20.6 & 26.3 & 16.6 & 57.1 & 0.56 \\
\hline & Equation [4d] & 35.0 & 12.1 & 6.06 & 81.8 & 0.46 \\
\hline & Equation [5d] & 35.4 & 26.3 & 16.6 & 57.1 & 0.56 \\
\hline & Equation [6d] & 37.7 & 7.62 & 10.1 & 82.2 & 0.38 \\
\hline & Equation [7d] & 29.5 & 8.46 & 4.36 & 87.2 & 0.59 \\
\hline & Equation [8d] & 28.2 & 8.01 & 5.67 & 86.3 & 0.63 \\
\hline & Kriss (1930) & 31.3 & 28.7 & 10.7 & 60.6 & 0.65 \\
\hline & Axelsson (1949) & 40.4 & 17.8 & 2.31 & 79.9 & 0.24 \\
\hline & Mills et al. (2003) linear 1 & 33.5 & 46.6 & 0.116 & 53.3 & 0.65 \\
\hline & Mills et al. (2003) linear 2 & 37.0 & 41.2 & 0.218 & 58.6 & 0.53 \\
\hline & Mills et al. (2003) linear 4 & 43.3 & 56.0 & 2.62 & 41.4 & 0.54 \\
\hline & Mills et al. (2003) nonlinear 1 & 28.9 & 25.3 & 5.12 & 69.6 & 0.66 \\
\hline & Mills et al. (2003) nonlinear 2 & 28.7 & 1.48 & 7.29 & 91.2 & 0.56 \\
\hline & Moe and Tyrrell (1979b) & 50.8 & 36.3 & 13.3 & 50.38 & 0.24 \\
\hline & Blaxter and Clapperton (1965) & 29.1 & 0.630 & 0.186 & 99.2 & 0.51 \\
\hline \multirow[t]{19}{*}{ Combined } & Equation $[1 \mathrm{c}]$ & 30.1 & 5.29 & 3.32 & 91.4 & 0.60 \\
\hline & Equation [2c] & 28.2 & 6.27 & 10.8 & 82.9 & 0.68 \\
\hline & Equation [3c] & 46.4 & 0.567 & 0.128 & 99.3 & 0.04 \\
\hline & Equation $[4 c]$ & 37.3 & 2.80 & 4.45 & 92.7 & 0.44 \\
\hline & Equation [5c] & 29.9 & 6.50 & 11.7 & 81.8 & 0.66 \\
\hline & Equation [6c] & 31.0 & 7.35 & 17.1 & 75.6 & 0.67 \\
\hline & Equation $[7 \mathrm{c}]$ & 29.7 & 5.61 & 5.98 & 88.4 & 0.63 \\
\hline & Equation [8c] & 34.1 & 6.07 & 17.2 & 76.7 & 0.60 \\
\hline & Equation [9c] & 29.6 & 8.20 & 18.6 & 73.2 & 0.71 \\
\hline & Equation [10c] & 30.5 & 5.79 & 16.2 & 78.0 & 0.67 \\
\hline & Kriss (1930) & 33.7 & 32.5 & 9.68 & 57.8 & 0.68 \\
\hline & Axelsson (1949) & 40.9 & 0.10 & 0.205 & 99.7 & 0.20 \\
\hline & Mills et al. (2003) linear 1 & 40.7 & 60.1 & 0.255 & 39.7 & 0.68 \\
\hline & Mills et al. (2003) linear 2 & 42.8 & 53.5 & 0.704 & 45.8 & 0.60 \\
\hline & Mills et al. (2003) linear 4 & 59.1 & 71.3 & 0.475 & 28.2 & 0.54 \\
\hline & Mills et al. (2003) nonlinear 1 & 32.6 & 32.8 & 4.748 & 62.4 & 0.68 \\
\hline & Mills et al. (2003) nonlinear 2 & 29.3 & 0.37 & 7.04 & 92.6 & 0.62 \\
\hline & Moe and Tyrrell (1979b) & 38.3 & 10.8 & 1.17 & 88.0 & 0.41 \\
\hline & Blaxter and Clapperton (1965) & 27.9 & 0.22 & 0.097 & 99.7 & 0.58 \\
\hline
\end{tabular}

${ }^{1}$ Root mean square prediction error (RMSPE) expressed as a percentage of the observed mean.

${ }^{2}$ Error due to bias, as a percentage of total RMSPE.

${ }^{3}$ Error due to regression, as a percentage of total RMSPE.

${ }^{4}$ Error due to disturbance, as a percentage of total RMSPE. 
of practical use when available model inputs are limited.

Although DMI and MEI appear to be adequate predictors of $\mathrm{CH}_{4}$ production on their own, a substantial level of variation is left unaccounted for by these models. There have been attempts to use more complex regression models with better descriptions of dietary composition (Wilkerson et al., 1995) with success, so regression analysis on our database was undertaken to determine which other factors contribute to improving the prediction of $\mathrm{CH}_{4}$ production.

\section{Multiple Regression Equations}

Several scenarios were set up in the current study from which $\mathrm{CH}_{4}$ prediction equations were developed. These included using either MEI or DMI, and measures of dietary variables expressed as either a percentage of DM or kilograms per day. However, a problem arose in using PROC MIXED when trying to develop equations based on dietary variables expressed as a percentage of DM, because for many of the studies, the percentage of DM of a variable was constant within a study (i.e., all animals were fed the same diet). The MIXED procedure would not converge on these data, or deemed them nonsignificant. An overall plot of $\mathrm{CH}_{4}$ production vs. percentage of DM for many of the variables did appear to have a significant relationship (Table 4). However, PROC CORR does not account for the random effects of study; therefore, these results are likely biased. In addition, this analysis does not consider the interaction between variables. The relationship between $\mathrm{CH}_{4}$ production and dietary variables expressed as a percentage of DM was interesting to look at because it gave an indication of the influence of the variable if DMI were held constant, similar to the idea of a forage:concentrate ratio. Once this percentage was multiplied by the DMI to convert the variable to kilograms per day, the resulting relationship included the effects of both the variable being evaluated and DMI. For example, because the relationship between $\mathrm{CH}_{4}$ production and DMI is positive, if the relationship between $\mathrm{CH}_{4}$ production and a given variable were negative, these two lines would multiply and cancel each other out, resulting in a zero slope for the line when the variable is expressed in kilograms per day. Similarly, if the $\mathrm{CH}_{4}$ production vs. variable (\%) line were positive, the $\mathrm{CH}_{4}$ production vs. variable $(\mathrm{kg} / \mathrm{d})$ line would become more positive, and if the $\mathrm{CH}_{4}$ production vs. variable (\%) line had a zero slope, the $\mathrm{CH}_{4}$ production vs. variable $(\mathrm{kg} / \mathrm{d})$ line would become slightly positive. Although kilograms per day is the more common way of expressing a dietary component intake, looking at the percentage of DM of a variable would tease out its influence from the effect of total
DMI. However, because the variable expressed as a percentage of DM did not consistently vary within the study, PROC MIXED equations could be developed only for variables expressed as kilograms per day.

The NDF fraction of a diet, evaluated here for inclusion in a $\mathrm{CH}_{4}$ prediction equation, is made up of cellulose, hemicellulose, lignin, and sometimes silica, and is commonly referred to as the cell-wall fraction (Van Soest et al., 1991). Neutral detergent fiber was positively correlated with $\mathrm{CH}_{4}$ production when expressed as kilograms per day; however, when expressed as a percentage of DM, the relationship was positive for only the beef database (Table 4). The negative correlation for the dairy and combined databases could be due to the relative proportions of cellulose, hemicellulose, and lignin that make up the NDF fraction. The positive correlation of $\mathrm{NDF}(\mathrm{kg} / \mathrm{d})$ with $\mathrm{CH}_{4}$ production is likely the result of increased ruminal fermentation, decreased rate of passage out of the rumen, and a favored high acetate:propionate ratio because of the actual NDF component and DMI (Hegarty and Gerdes, 1998; Benchaar et al., 2001; Boadi et al., 2004). Neutral detergent fiber $(\mathrm{kg} / \mathrm{d})$ showed a high correlation with $\mathrm{CH}_{4}$ production for the beef database $\left(\mathrm{R}^{2}=0.63\right)$, and comparably high values for the dairy and combined databases $\left(\mathrm{R}^{2}=\right.$ 0.44 and 0.42 , respectively; Table 4 ), suggesting that it may be an easily measured variable useful as a predictor of $\mathrm{CH}_{4}$ production within a regression equation.

Acid detergent fiber (the fraction containing cellulose, lignin, and silica), a less desirable measure of fiber than NDF (NRC, 2001), although examined because it is commonly measured, was negatively related to $\mathrm{CH}_{4}$ production when expressed as a percentage of DM for the dairy and combined databases $\left(R^{2}=0.39\right.$, and 0.061 , respectively), but was positively related to $\mathrm{CH}_{4}$ production for the beef database $\left(R^{2}=0.19\right.$; Table 4$)$. When expressed as kilograms per day, ADF was positively related to $\mathrm{CH}_{4}$ production for the beef, dairy, and the combined databases $\left(R^{2}=0.55,0.34\right.$, and 0.36 , respectively; Table 4).

Lignin, another frequently measured variable, is a noncarbohydrate component that binds to cellulose and hemicellulose, decreasing their availability and strengthening the structure of the plant cell wall (Van Soest, 1994). Lignin was significantly negatively related to $\mathrm{CH}_{4}$ production when expressed as a percentage of DM $(P<0.05$; Table 4$)$; however, when expressed as kilograms per day, lignin was positively related to $\mathrm{CH}_{4}$ production but was not significant (Table 4). When lig$\operatorname{nin}(\mathrm{kg} / \mathrm{d})$ was included in a complex regression equation (e.g., equation [11b]), its effect on overall $\mathrm{CH}_{4}$ production was negative. The negative relationship between lignin and $\mathrm{CH}_{4}$ production was likely through its limiting effect on digestion of cellulose and hemicel- 
lulose, thus limiting $\mathrm{CH}_{4}$ production by the rumen microbes.

It would have been desirable to have a description of the NFC component of the ration, composed of starches, sugars, and pectin, because similar components have been shown to be good predictors of $\mathrm{CH}_{4}$ production (Moe and Tyrrell, 1979b, used NSC and Mills et al., 2003, used starch). However, NFC was not commonly reported, and attempts to calculate it as $\mathrm{NFC}=100-$ $(\mathrm{CP}+\mathrm{EE}+\mathrm{ash}+\mathrm{NDF})$ often resulted in unrealistic values, likely because at least one of the variables was from an average book value. Therefore, NFC was not included in the analysis. The fermentation of cell wall carbohydrates generally produces more $\mathrm{CH}_{4}$ than the fermentation of soluble sugars, which generally produces more $\mathrm{CH}_{4}$ than the fermentation of soluble starch (Johnson et al., 1996). Although NFC, starch, sugar, and pectin are good predictors of $\mathrm{CH}_{4}$ production, these variables are seldom measured in North America, so application of the $\mathrm{CH}_{4}$ prediction equation based on these variables may be severely limited.

Ether extract was positively related to $\mathrm{CH}_{4}$ production when expressed as kilograms per day, and nonsignificantly related to $\mathrm{CH}_{4}$ production when expressed as a percentage of DM (Table 4). High levels of dietary fat have been shown to depress $\mathrm{CH}_{4}$ production (MJ/d) through biohydrogenation of unsaturated fatty acids (Dong et al., 1997; Machmuller and Kreuzer, 1999), decreased fiber degradation, and decreasing the amount of OM fermentable in the rumen (Mathison, 1997). When EE (kg/d) was included in a regression equation (e.g., equation [12b]), its effect on overall $\mathrm{CH}_{4}$ production became negative.

Forage proportion in the diet has also been used to predict $\mathrm{CH}_{4}$ production (Benchaar et al., 2001; Mills et al., 2003). Johnson and Johnson (1995) reported that very low forage diets $(<10 \%)$ typically lose between 2 and $3 \%$ of gross energy intake as $\mathrm{CH}_{4}$, whereas the accepted average for more modest diets is $6 \%$. A significant positive relationship existed between $\mathrm{CH}_{4}$ production and forage proportion for the beef database (Table 4), whereas a significant negative relationship existed for the dairy database when all data points were included (Table 4). However, when 100\% forage diet data points were removed from the dairy database, the relationship became significantly positive (Table 4). The combination of the positive relationship for the beef data, which covered lower values (down to 9\% forage), and the negative relationship for the dairy data (with all data points), which covered mainly higher values ( $>40 \%$ forage), resulted in a significant nonlinear relationship in the combined database. Analysis using the nonlinear mixed procedure showed that the relationship between $\mathrm{CH}_{4}$ production and forage proportion in the diet for the combined database could be described by the relationship $\mathrm{CH}_{4}(\mathrm{MJ} / \mathrm{d})=-0.00103 \times(\text { forage } \%)^{2}$ $+0.110 \times($ forage $\%)+8.89$. However, there was a high RMSPE value associated with the equation (RMSPE = 46.3\%; ED $=30.4 \%)$. Lovett et al. (2003) observed a quadratic response of methane emissions to decreasing forage percentage of the diet, in agreement with the results of Moss et al. (1995). Rumen simulations performed by Benchaar et al. (2001) showed that $\mathrm{CH}_{4}$ production $(\mathrm{MJ} / \mathrm{d})$ increased when the percentage of forage in the diet was increased from 30 to $80 \%$, and declined thereafter. The authors suggested that this was due to increased ruminal passage rate, decreased ruminal digestion of starch, increased digestion of NDF, and increased ruminal microbial efficiency. Decreasing the forage percentage of the diet also resulted in a shift in ruminal fermentation toward propionate production and decreased ruminal $\mathrm{pH}$ (Fahey and Berger, 1988). Propionate production favors competitive pathways for $\mathrm{H}_{2}$ use in the rumen, and would therefore decrease overall $\mathrm{CH}_{4}$ production (Hegarty, 1999; Moss et al., 2000).

The linear 4 equation of Mills et al. (2003) uses forage proportion of the diet in addition to DMI to predict $\mathrm{CH}_{4}$ production, similar to some of the equations developed here (Table 5). However, among the extant equations, this equation had the highest RMSPE values when challenged against our database (Table 6). Significant variation existed in the relationship between forage proportion and $\mathrm{CH}_{4}$ production, and this was likely due to variability in the composition of the forage and concentrate fractions within the ratio.

\section{Comparison of Models}

Regression equations developed from the beef, dairy, and combined databases are presented in Table 5, and the results of the RMSPE analysis of them are presented in Table 6. For the beef database, examination of the equations with one variable (equations [1b] to [6b]) revealed that equations [5b] and [6b] [based on $\mathrm{NDF}(+)$ and $\mathrm{ADF}(+)$, respectively, where (+) indicates a positive relationship] were the best predictors of $\mathrm{CH}_{4}$ production in terms of RMSPE (RMSPE\% $=22.3$ and 24.3 , respectively). The ADF equation had $96 \%$ of its error from random sources (Table 6). Of the equations with 2 variables (equations [7b] to [12b]), equations [11b] and [7b] had the lowest RMSPE values (RMSPE\% $=18.7$ and 20.6, respectively) and included the effects of DMI (+) and lignin (-), and MEI (+) and NDF (+), respectively [where (-) indicates a negative relationship; Table 6]. Of the equations with 3 variables (equations [13b] and [14b]) equation [14b], with the effects of MEI (+), ADF (+), and lignin (-), resulted in 
the lowest RMSPE value (14.4\%) and 88\% of error from random sources (Table 6).

For the dairy database, examination of the equations with one variable (equations [1d] to [5d]) revealed that equations [3d] and [2d] [based on forage\% $(+)$ and DMI $(+)$, respectively] were the best predictors of $\mathrm{CH}_{4}$ production in terms of RMSPE (RMSPE\% $=20.6$ and 25.6, respectively), where the forage equation excluded $100 \%$ forage data sets, and the DMI equation had $91 \%$ of its error from random sources (Table 6). Of the equations with 2 variables (equations [6d] and [7d]), equation [7d] had the lowest RMSPE value $(\mathrm{RMSPE} \%=29.5)$ and included the effects of MEI (+) and NDF (-) (Table 6). The equation with 3 variables (equation [8d]), with the effects of DMI (+), ADF (-) and NDF (+), resulted in an RMSPE value of 28.2 and $86 \%$ of error from random sources (Table 6). Whereas increasing the complexity of the equation for the beef database reduced the RMSPE value, increasing the complexity for the dairy database did not increase predictions significantly.

When the beef and dairy databases were combined, examination of the equations with one variable (equations [1c] to [4c]) revealed that equation [2c], based on DMI (+), was the best predictor of $\mathrm{CH}_{4}$ production in terms of RMSPE (RMSPE\% $=28.2$ ), and had $83 \%$ of its error from random sources. Of the equations with 2 variables (equations [5c] to [8c]), equations [7c] and [5c] had the lowest RMSPE values (RMSPE\% $=29.7$ and 29.9 , respectively) and included the effects of MEI (+) and NDF (+), and MEI (+) and forage (+), respectively (Table 6). Of the equations with 3 variables (equations [9c] and [10c]), equation [9c], with the effects of DMI $(+)$, NDF (+), and lignin (-), resulted in the lowest RMSPE value (RMSPE\% $=29.6)$ and had $73 \%$ of error from random sources (Table 6). No added advantage in terms of RMSPE was achieved by increasing the complexity of the equations for the combined database, likely because of the carryover effect from the dairy database. Some of the simpler equations had lower RMSPE values than the more complex equations.

Overall, equation [14b] had the lowest RMSPE value for the beef database, equation [3d] for the dairy database, and equation [2c] for the combined database. The lower RMSPE values achieved with more complex equations for the beef database was likely the result of a wider range of diets within the beef database and thus more variability. It could also be due to the relatively weaker relationship between $\mathrm{CH}_{4}$ production and DMI for the beef database compared with the dairy database. In this case, the addition of other variables to the model improved its predictive ability.

The weaker relationships and higher variability for the beef database could be caused by several factors. First, the dairy database is mostly calorimetry data, whereas the beef database is fairly equally divided between calorimetry and $\mathrm{SF}_{6}$ data. It is possible that combining techniques could introduce variability, and perhaps with a larger database of calorimetry vs. $\mathrm{SF}_{6}$ data, the effect of constructing regression equations based on one vs. the other method could be determined. Second, although most dairy cows are housed in confinement, beef cows can be confined in a feedlot or on pasture with correspondingly different diets that will vary more than dairy cow diets (Basarab et al., 2005). Although the cows included in the dairy database were all in the same physiological state (lactating), beef cows could be in a cow-calf (lactating), backgrounding, or feedlot operation and vary more in age, gender, BW, and ADG. Either of these explanations could suggest that these equations may need to be reexamined against a larger current beef database, possibly divided into cow-calf, feeder-stocker, and feedlot scenarios separating by collection technique, as was started by Nkrumah et al. (2006).

The extant equations of Blaxter and Clapperton (1965), Mills et al. (2003; linear 4), and Moe and Tyrrell (1979b) all used information on the composition of diet to improve the prediction of $\mathrm{CH}_{4}$ production and can be compared with the equations developed in this study as well as against each other. These equations were selected because they are commonly used and the required inputs are obtainable from the database compiled here or from North American book values.

Estimates of gross energy digestibility at maintenance intake, required for the equation of Blaxter and Clapperton (1965, adjusted by Wilkerson et al., 1995), are not commonly measured and were estimated as gross energy digestibility at production level intakes for most of the data. Despite this, the equation of Blaxter and Clapperton (1965) does well when challenged against the northern American database. Mean square prediction error values were comparable to those of the newly developed equations, and relatively high proportions of error came from random sources (Table 6), particularity for the beef database. Conversely, the equation of Moe and Tyrrell (1979b) generally had high RMSPE values in all the databases (Table 6). Many of the inputs for this equation (cellulose, hemicellulose, and NSC) were average book values because they were not reported in the published papers, and this might have affected its predictive ability. In addition, these variables were reported in feed tables for only a limited number of feeds; thus, assumptions were made and the accuracy of these estimates was likely low. However, Moe and Tyrrell (1979b) showed these dietary variables to be highly correlated with $\mathrm{CH}_{4}$ production. Contrary to the results of the current study, Wilkerson et al. (1995) found that the equation of Moe and Tyrrell 
(1979b) performed better than several other equations. However, this is part of the limitation of this equation; although it may predict $\mathrm{CH}_{4}$ production well, the inability to obtain accurate input values makes it a less practical choice.

Overall, for the beef database, among the extant equations, the equation of Blaxter and Clapperton (1965) performed the best in terms of the lowest RMSPE value $(\mathrm{RMSPE} \%=19.1, \mathrm{ED}=79 \%)$, followed by the nonlinear 2 equation of Mills et al. (2003; RMSPE\% = $28.7, \mathrm{ED}=95 \%$; Table 6). For the dairy database, the nonlinear 2 equation of Mills et al. (2003) had the lowest RMSPE value (RMSPE\% = 28.7, ED = 91\%), followed closely by the nonlinear 1 equation of Mills et al. (2003) and equation of Kriss (1930; Table 6). For the combined database, the equation of Blaxter and Clapperton (1965) had the lowest RMSPE value (RMSPE\% = 27.9, $\mathrm{ED}=100 \%$ ), again followed by the nonlinear 2 equation of Mills et al. (2003; RMSPE\% = 29.3, ED = 93\%; Table 6).

The average RMSPE (\%) values for the beef database were 24.6 and 44.9 for the new and extant equations, respectively. For the dairy database, average RMSPE (\%) values were 30.2 and 35.9 for the new and extant equations, respectively. For the combined database, the average RMSPE (\%) values were 32.7 and 38.4 for the new and extant equations, respectively. For all 3 databases, numerical decreases in the RMPSE were obtained with the newly developed equations.

Newly developed individual equations had the lowest RMSPE values (compared with extant models) for the beef and dairy databases (equations [14b] and [3d], respectively; Table 6), and came a close second for the combined dairy database (equation [2c] and the equation of Blaxter and Clapperton, 1965; Table 6).

Although the average MSPE for the new models vs. the extant models was consistently numerically lower for all databases (see above), a simple Student's $t$-test, assuming unequal variance, showed that the lower average MSPE value difference was significant only for the beef database $(P=0.013,0.099$, and 0.137 , for the beef, dairy, and combined databases, respectively).

It appears that the new models performed comparably to, if not slightly better than, the extant models. They were also, for the most part, simpler equations containing input variables more easily obtainable at the farm level. The simplicity and easily obtainable input variables may make the new equations preferable over the extant models, although they should also be challenged on an external database.

\section{CONCLUSIONS}

Several $\mathrm{CH}_{4}$ production prediction equations were developed in this study that adequately predicted $\mathrm{CH}_{4}$ production from northern American cattle on typical northern American diets. These equations could be useful to the livestock industry for accurately predicting $\mathrm{CH}_{4}$ production from a minimum set of inputs. Dry matter intake, $\mathrm{NDF}, \mathrm{ADF}$, forage proportion, and lignin appear to be useful dietary factors for predicting $\mathrm{CH}_{4}$ production. The limitation of using some of the extant models, such as the equation of Moe and Tyrrell (1979b), was the difficulty of obtaining reliable model input variables, which might have compromised their predictive ability in this study. Although the extant models evaluated performed adequately and can be used if input values are available, the new equations developed in the current study showed an improvement in prediction and increased ease of use, and are therefore preferable when considering mitigation options or calculations of national methane emissions inventory.

\section{REFERENCES}

Axelsson, J. 1949. The amount of produced methane energy in the European metabolic experiments with adult cattle. Ann. R. Agric. Coll. Sweden 16:404-419.

Basarab, J. A., E. K. Okine, V. S. Baron, T. Marx, P. Ramsey, K. Ziegler, and K. Lyle. 2005. Methane emissions from enteric fermentation in Alberta's beef cattle population. Can. J. Anim. Sci. 85:501-512.

Beauchemin, K. A., and S. M. McGinn. 2005. Methane emissions from feedlot cattle fed barley or corn diets. J. Anim. Sci. 83:653-661.

Belyea, R. L., P. J. Marin, and H. T. Sedgwick. 1985. Utilization of chopped and long alfalfa by dairy heifers. J. Dairy Sci. 68:1297-1301.

Benchaar, C., C. Pomar, and J. Chiquette. 2001. Evaluation of dietary strategies to reduce methane production in ruminants: A modelling approach. Can. J. Anim. Sci. 81:563-574.

Bibby, J., and H. Toutenburg. 1977. Prediction and Improved Estimation in Linear Models. John Wiley and Sons, Chichester, UK.

Birkelo, C. P., D. E. Johnson, and G. M. Ward. 1986. Net energy value of ammoniated wheat straw. J. Anim. Sci. 63:2044-2052.

Blaxter, K. L., and J. L. Clapperton. 1965. Prediction of the amount of methane produced by ruminants. Br. J. Nutr. 19:511-521.

Boadi, D. A., and K. M. Wittenberg. 2002. Methane production from dairy and beef heifers fed forages differing in nutrient density using the sulphur hexafluoride (SF6) tracer gas technique. Can. J. Anim. Sci. 82:201-206.

Boadi, D. A., K. M. Wittenberg, and W. P. McCaughey. 2002. Effects of grain supplementation on methane production of grazing steers using the sulphur (SF6) tracer gas technique. Can. J. Anim. Sci. 82:151-157.

Boadi, D. A., K. M. Wittenberg, S. L. Scott, D. Burton, K. Buckley, J. A. Small, and K. H. Ominski. 2004. Effect of low and high forage diet on enteric and manure pack greenhouse gas emissions from a feedlot. Can. J. Anim. Sci. 84:445-453.

Conrad, J. H., C. W. Deyoe, L. E. Harris, P. W. Moe, and P. J. Van Soest. 1982. United States-Canadian Table of Feed Composition. Natl. Acad. Press, Washington, DC.

Coppock, C. E., W. P. Flatt, and L. A. Moore. 1964. Effect of hay to grain ratio on utilization of metabolizable energy for milk production by dairy cows. J. Dairy Sci. 47:1330-1338.

Der, G., and B. S. Everitt. 2002. A Handbook of Statistical Analysis Using SAS. 2nd ed. Chapman and Hall/CRC Press, Boca Raton, FL.

Dong, Y., H. D. Bae, T. A. McAllister, G. W. Mathison, and K. L. Cheng. 1997. Lipid-induced depression of methane production and digestibility in the artificial rumen system (RUSITEC). Can. J. Anim. Sci. 77:269-278. 
Environment Canada. 2005. Multilateral Environmental Agreements: UN Framework Convention on Climate Change (UNFCCC) and Kyoto Protocol to the Convention. Available: http://www.ec.gc.ca/international/multilat/unfccc_e.htm Accessed March 14, 2006.

Fahey, G. C., and L. L. Berger. 1988. Carbohydrate nutrition in ruminants. Pages 269-297 in The Ruminant Animal: Digestive Physiology and Nutrition. D. C. Church, ed. Prentice-Hall, Englewood Cliffs, NJ.

Hegarty, R. S. 1999. Reducing rumen methane emissions through elimination of rumen protozoa. Aust. J. Agric. Res. 50:1321-1327.

Hegarty, R. S., and R. Gerdes. 1998. Hydrogen production and transfer in the rumen. Rec. Adv. Anim. Nutr. 12:37-44.

Hironaka, R., G. W. Mathison, B. K. Kerrigan, and I. Vlach. 1996 The effect of pelleting of alfalfa hay on methane production and digestibility by steers. Sci. Total Environ. 180:221-227.

Holter, J. B., J. A. Bullis, and H. H. Hayes. 1986. Predicting maternal protein and fat balances of growing and mature dry cows. J. Dairy Sci. 69:2622-2635.

Holter, J. B., H. H. Hayes, W. E. Urban, and A. H. Duthie. 1992. Energy balance and lactation response in Holstein cows supplemented with cottonseed with or without calcium soap. J. Dairy Sci. 75:1480-1494.

Holter, J. B., M. J. Slotnick, H. H. Hayes, and C. K. Bozak. 1990. Effect of prepartum dietary energy on condition score, postpartum energy, nitrogen partitions, and lactation production responses. J. Dairy Sci. 73:3501-3511.

IPCC (Intergovernmental Panel on Climate Change). 2001. Climate Change 2001: The Scientific Basis. Cambridge Univ. Press, Cambridge, UK.

Johnson, D. E., G. W. Ward, and J. J. Ramsey. 1996. Livestock Methane: Current Emissions and Mitigation Potential. Lewis Publishers, New York, NY.

Johnson, K. A., and D. E. Johnson. 1995. Methane emissions from cattle. J. Anim. Sci. 73:2483-2492.

Kebreab, E., K. Clark, C. Wagner-Riddle, and J. France. 2006. Methane and nitrous oxide emissions from Canadian animal agriculture: A review. Can. J. Anim. Sci. 86:135-158.

Kriss, M. 1930. Quantitative relations of the dry matter of the food consumed, the heat production, the gaseous outgo, and the insensible loss in body weight of cattle. J. Agric. Res. 40:283-295.

Lovett, D., S. Lovell, L. Stack, J. Callan, M. Finlay, J. Conolly, and F. P. O'Mara. 2003. Effect of forage/concentrate ratio and dietary coconut oil level on methane output and performance of finishing beef heifers. Livest. Prod. Sci. 84:135-146.

Machmuller, A., and M. Kreuzer. 1999. Methane suppression by coconut oil and associated effects on nutrient and energy balance in sheep. Can. J. Anim. Sci. 79:65-72.

Mathison, G. W. 1997. Effect of canola oil on methane production in steers. Can. J. Anim. Sci. 77:545-546. (Abstr.)

McCaughey, W. P., K. Wittenberg, and D. Corrigan. 1997. Methane production by steers on pasture. Can. J. Anim. Sci. 77:519-524.

McCaughey, W. P., K. Wittenberg, and D. Corrigan. 1999. Impact of pasture type on methane production by lactating beef cows. Can. J. Anim. Sci. 79:221-226.

McGinn, S. M., K. A. Beauchemin, T. Coates, and D. Colombatto. 2004. Methane emissions from beef cattle: Effects of monensin, sunflower oil, enzymes, yeast, and fumaric acid. J. Anim. Sci. 82:3346-3356.

Mills, J. A. N., E. Kebreab, C. M. Yates, L. A. Crompton, S. B. Cammell, M. S. Dhanoa, R. E. Agnew, and J. France. 2003. Alternative approaches to predicting methane emissions from dairy cows. J. Anim. Sci. 81:3141-3150.

Moe, P. W., and H. F. Tyrrell. 1977. Effects of feed intake and physical form on energy value of corn in timothy hay diets for lactating cows. J. Dairy Sci. 60:752-758.

Moe, P. W., and H. F. Tyrrell. 1979a. Effect of endosperm type on incremental energy value of corn grain for dairy cows. J. Dairy Sci. 62:447-454.
Moe, P. W., and H. F. Tyrrell. 1979b. Methane production in dairy cows. J. Dairy Sci. 62:1583-1586.

Moe, P. W., H. F. Tyrrell, and N. W. Hooven. 1973a. Energy balance measurements with corn meal and ground oats for lactating cows. J. Dairy Sci. 56:1149-1153.

Moe, P. W., H. F. Tyrrell, and N. W. Hooven. 1973b. Physical form and energy value of corn grain. J. Dairy Sci. 56:1298-1304.

Moss, A. R., D. L. Givens, and P. C. Garnsworthy. 1995. The effect of supplementing grass silage with barley on digestibility, in sacco degradability, rumen fermentation and methane production in sheep at two levels of intake. Anim. Feed Sci. Technol. 55:9-33.

Moss, A. R., J.-P. Jouany, and J. Newbold. 2000. Methane production by ruminants: Its contribution to global warming. Ann. Zootech. 49:231-253.

NRC (National Research Council). 1996. Nutrient Requirements of Beef Cattle. National Academy Press, Washington, DC.

NRC (National Research Council). 2001. Nutrient Requirements of Dairy Cattle. National Academy Press, Washington, DC.

Nkrumah, J. D., E. K. Okine, G. W. Mathison, K. Schmid, C. Li, J. A. Basarab, M. A. Price, Z. Wang, and S. S. Moore. 2006. Relationships of feedlot feed efficiency, performance, and feeding behaviour with metabolic rate, methane production, and energy partitioning in beef cattle. J. Anim. Sci. 84:145-153.

Okine, E. K., G. W. Mathison, and R. T. Hardin. 1989. Effects of changes in frequency of reticular contractions on fluid and particulate passage rates in cattle. J. Anim. Sci. 67:3388-3396.

Reynolds, C. K., and H. F. Tyrrell. 2000. Energy metabolism in lactating beef heifers. J. Anim. Sci. 78:2696-2705.

Reynolds, C. K., H. F. Tyrrell, and P. J. Reynolds. 1991. Effects of diet forage-to-concentrate ratio and intake on energy metabolism in growing beef heifers: Whole body energy and nitrogen balance and visceral heat production. J. Nutr. 121:994-1003.

SAS Institute. 2000. SAS User's Guide. Statistics. SAS Inst. Inc., Cary, NC.

Sauer, F. D., V. Fellner, R. Kinsman, J. K. G. Kramer, H. A. Jackson, A. J. Lee, and S. Chen. 1998. Methane output and lactation response in Holstein cattle with monensin or unsaturated fat added to the diet. J. Anim. Sci. 76:906-914.

St-Pierre, N. R. 2001. Invited review: Integrating quantitative findings from multiple studies using mixed model methodology. J. Dairy Sci. 84:741-755.

Tyrrell, H. F., and P. W. Moe. 1971. Net energy value for lactation of a high and low concentrate ration containing corn silage. J. Dairy Sci. 55:1106-1112.

Tyrrell, H. F., D. J. Thomson, D. R. Waldo, H. K. Goering, and G. L. Haaland. 1992. Utilization of energy and nitrogen by yearling Holstein cattle fed direct-cut alfalfa or orchard grass ensiled with formic acid plus formaldehyde. J. Anim. Sci. 70:3163-3177.

Van Soest, P. J. 1994. Nutritional Ecology of the Ruminant. 2nd ed. Cornell Univ. Press, Ithaca, NY.

Van Soest, P. J., J. B. Robertson, and B. A. Lewis. 1991. Methods for dietary fiber, neutral detergent fiber, and nonstarch polysaccharides in relation to animal nutrition. J. Dairy Sci. 74:35833597.

Varga, G. A., H. F. Tyrrell, G. B. Huntington, D. R. Waldo, and B. P. Glenn. 1990. Utilization of nitrogen and energy by Holstein steers fed formaldehyde- and formic acid-treated alfalfa or orchard grass silage at two intakes. J. Anim. Sci. 68:3780-3791.

Waldo, D. R., H. F. Tyrrell, A. V. Capuco, and C. E. Rexroad. 1997. Components of growth in Holstein heifers fed either alfalfa or corn silage diets to produce two daily gains. J. Dairy Sci. 80:1674-1684.

Westberg, H., and B. Lamb. 2001. Inventory of methane emissions from US cattle. J. Geophys. Res. 106:633-642.

Wilkerson, V. A., D. P. Casper, and D. R. Mertens. 1995. The prediction of methane production of Holstein cows by several equations. J. Dairy Sci. 78:2402-2414. 